American Journal of Engineering Research (AJER)

e-ISSN : 2320-0847 p-ISSN : 2320-0936

Volume-02, Issue-12, pp-494-499

www.ajer.org

\title{
Analysis of fatigue in the weld of the joints in the fixed offshore platforms
}

\author{
Roberto Taier ${ }^{(1)}$ \\ coautores: Ernani Carlos de Araújo and Leonard Godefroid ${ }^{(2)}$
}

\begin{abstract}
Four tubular joints of a fixed offshore platform are modelled using finite elements to evaluate respective fatigue lives and comparison with the results obtained from conventional models in frame elements. Stress concentration factors (SCF's) calculated from parametric formulas are also compared with those obtained from finite elements models.

The results of this work have the intention of verifying the validity of the refinement of fatigue analysis on critical joints of platforms and the evaluation of its consequences in the inspection plan.

Results show that finite elements analysis is recommended for joints whose type and/or behaviour is not consistent with standard models, used by computational programs. From four analised joints, two of them would not need to be part of inspection plan.
\end{abstract}

\section{Keywords: - offshore platform, steel, tubular joint, SCF, Finite Elements.}

\section{I}

\section{INTRODUCTION}

1.1 Generalization about fatigue.

Several devices of machine, vehicle and structures are frequently actions by cycle loads by time. These loads provoke cicle stresses that, even to bing little intensive, can provoke physics rupture on the material, to make some fracture. This situation that provoke the rupture of material by cycle loads is named fatigue.

The fatigue has been studied and searched for 175 years by cientists all the word.

On offshore platforms, the costs of the manufacturing are $50 \%$ by manufacturing of situations of services are for inspections to see fracture and fatigue. The best of such procedures for inspections are to make structural analyse of confiability, evaliations of consequences of fracture and fatigue by calculations more specifics for fatigue to check the critical areas on the structures.

$1.2 \quad-$ Kinds of Offshore Structures.

There are two kinds of seaside platforms for petroleum production fixed one, and with freedom of movegnert one.
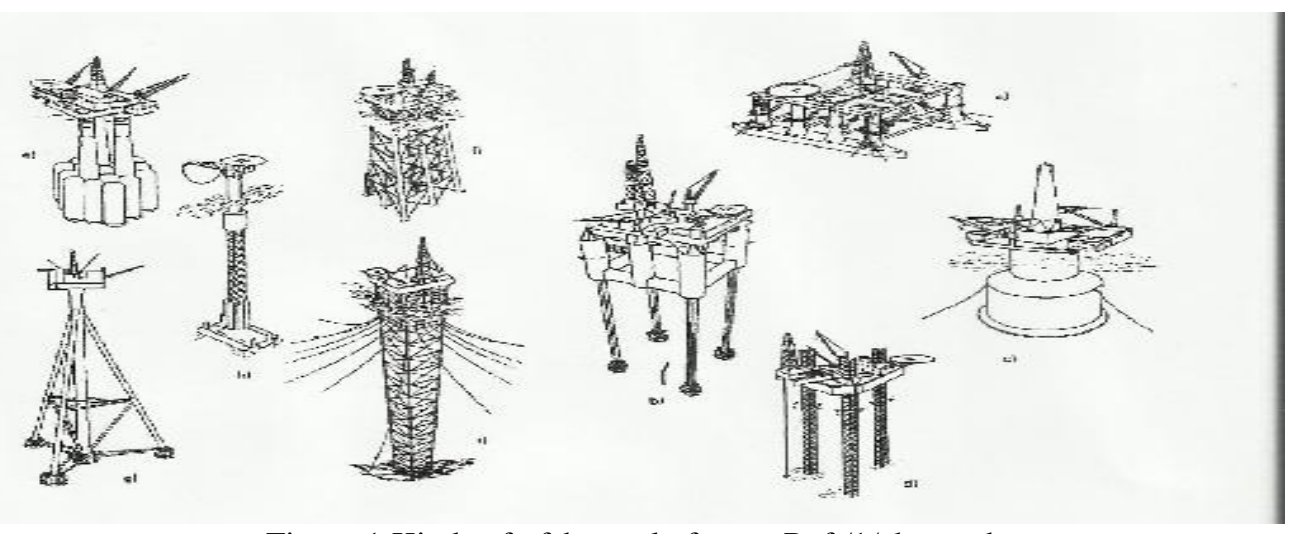

Figure 1 Kinds of ofshore platforms, Ref /1/changed 
a-semi-submerse;

b - traction lag;

c - buoy;

d - autoclevatad;

e - fixed by gravitation;

$\mathrm{f}$ - Kind of jaqueta;

$\mathrm{g}$ - steel tetraedro;

$\mathrm{h}$ - articulated tower;

$\mathrm{i}$ - staiad tower

\section{$1.3-$ Joints on ofshore structures.}

Steel Ofshore structures normaly consisted of tubular elements with thin walls because the closed sections to allow pushing and high rigid tortion, minimum surfasse for paint and corrosion, simple of shape and fine look. In the sumerse parto $\mathrm{f}$ thse structures, are projected circular tubes because to give smaller hidrodinamic forces then sections retangular and square tubular members.
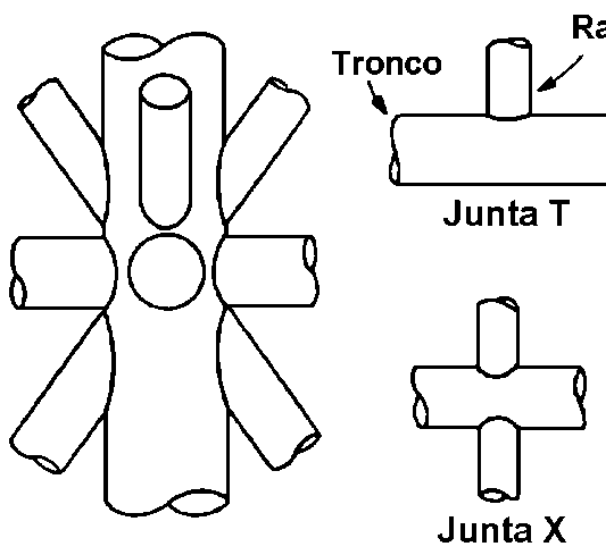

Ramificação
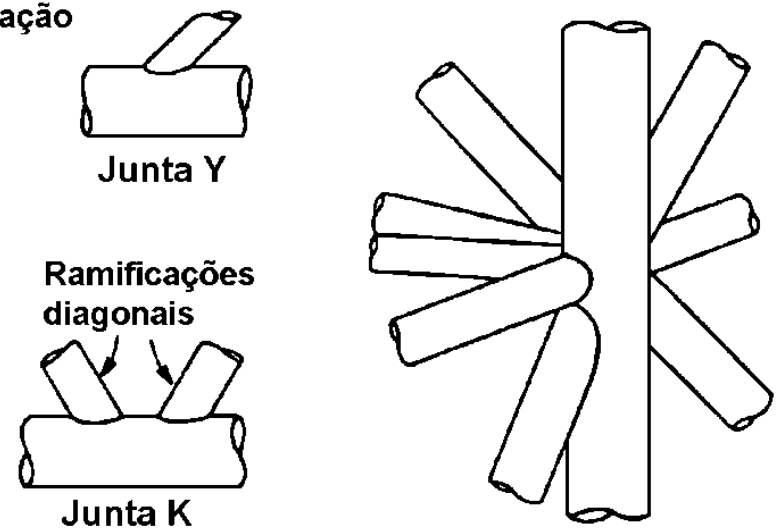

Figure 2: welded Samples tubular joints plan and multiplan

\section{FATIGUE IN FIXED OFFSHORE PLATFORMS}

The analyse of conditions that can provoke rupture by fatigue in offshore structures is a complex work, that to envolve the to know of any áreas of ocean, hidrodinamic, advance analise of stress, fracture mecanic and material tecnologie. For to make a analyse of fatigue of a maritme structure kind offshore is necessary:

To choose a structural model apropriate;

To apply a apropriate método of structural método;

To determine the SCF's for local analise or trough parametric expressions;

To predict the life using the $\mathrm{S}-\mathrm{N}$ curves with the MINER's rule for accumulate damage;

The objectives of analise are:

To avoid that occur fracture by fatigue;

To calculate the useful life of each elemento or joint of structure;

To establishment comparision parameter ( life or rupture acumulated) for inspection plane.

The avaliation of fatigue should to be consider all actions that provoque vary of stress, or: waves, are the bigger source that promove fatigue.

\section{SOURCE OF PLATFORM FOR ANALYSIS}

\section{$1.4 \quad$ - General explain of platform.}

The platform of Cherne 2 - PCH -2, belong when Campo de Cherne, situation in the Bacia de Campos, in the coast of Rio de Janeiro, state from Brazil and its foundation made in 1982. This is a fixed platform and its foundation are in steel, compound of the jaqueta, deck and stake.The look of jaqueta is same with a spacial frame with members of tubular circular section, for overcome a submerse water of $142 \mathrm{~m}$.

\section{5 - Results of fatigue analise}

The analise is of kind deterministic, for a useful life of 30 years, with safety fator equal 2. Are to make 3 diferents analysis:

Analysi by ADEP; 
Análysi by ADEP with SCF's of Wordsworth;

Análysi by SAC 's with SCF's of Efthymion.

The results in the table I show the life without the safety fator. In the all the cases, was adopt 2,50 forthe SCF's. Was adopted the X curve of API -RP2A that show life low 60 years and by this, was of the plano $\mathrm{f}$ inspect of platform.The joints inspect are situations in the follow levels:

Joint 5.600: (-) 5,25 m; joint 121: ( -)142,00 m;

Joint 429: (-) 46,50 m; joint 555: ( -)19,00 m;

\section{6 - Crest of Point Métod:}

\section{CREST OF STRESS TROUGH OF FINITES ELEMENTS MODELS}

To know that is dificult to make the calculation of a stress in the weld by distracted significant ofgeometrie in the local, with diferentes kind of imperfect. This distracted is more efcience trough use of a $\mathrm{S}-\mathrm{N}$ apropriate curve.So for analise of Project is used a numerical simple procedure, for excuse the necessity of models very large, with grade very discretizations, where the concentractions of stress or uneven of weld stay in the $\mathrm{S}-\mathrm{N}$ curve. This is named Crest of Point.

\section{7 - Stress of Crest in Tubular Joint}

The DNV RP -C203, Ref./2/ Norm, the analysi trough of shell elements can to be used and, so, the modelo $f$ weld is not include in the model. In this case,the question is to make how and where must to be calculated the stress of Crest. There are any tecnics of extrapoltions for obtain this stress and, in this work are adoted the recomendations of DNV RP - C203 Norm.

For to be appropriate the growth of geometrics stress, is importante that the stresses in the joints of reference situateds the $t / 2$ and $3 t / 2$ from of intersection line of members no to be in of the same elemento. This show that the elements must to be approximate equal the tikness of wall oftube, in the áreas of stress concentration. The stress must to be calculated in the surfaces of the shells for consideration of flexion in the elements.

For the preservation the information of direction of principals stresses in the área of crest, must to be use the componentes of stress for the extrapolation. When isn't included the geometrie of weld model, the extrapolation must to be to maked antil the line of intersection of average surfasse of members. This method of of that to make extrapolation the stress in the points of Gaussiana integration antil the average surfasse of the shape. Apart from a extrapolation by line of growth of stress. The end extrapolation of componentes ofr stresses is to maked by $3 t / 2$ of line from this localizations to distance of $t / 2$ and shape/ with show the figure 3 . Has been to maked extrapolation the principals stresses for computer the fatigue. The vary of stresses of cresto $f$ tubular joints must to be combined with $\mathrm{T}$ curve, that use the thikness of member.
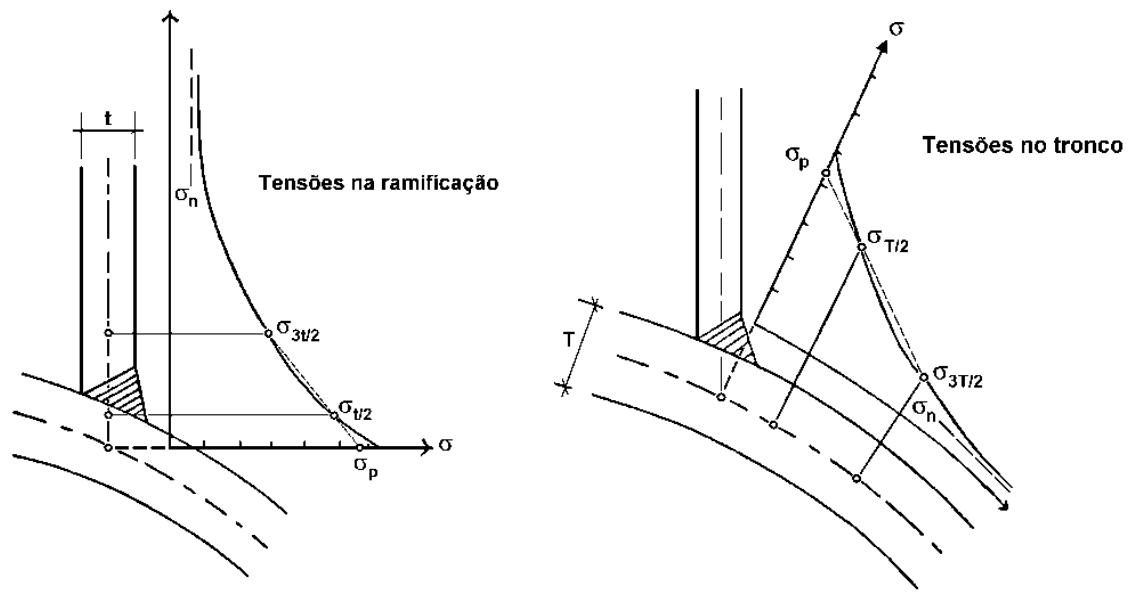

Figure 3 - Model for extrapolation for cresto f stress

V.

5.1 - Kinds of Model and Extrapolation

MODEL IN FINITE ELEMENTS

The models are to maked all of shells elements did locate in the average surfasse of tubes members, so that joints are showed by intersections of this surfaces. The méthod of extrapolation recommended determined that alones componentes of stresses, for to be named with crest stress the principals stresses máximum results from 
several path of extrapolation. In general, the use of máximum principal stresses result a conservative SCE and the life of fatigue and is, so, adoped in this work.

\section{2 - Plan and Characteristic of models}

The software ANSYS, instalated in the UFOP is utilized in the models and analysis by finite elements. In the to make of discretizations is used the shell Finite elemento SHELL63, that have 4 knots, with 6 freedon degrees by knots. For comparations of values of SCF 's, the grade of discretizations for isoparametric element SHELL93 that have 8 knots with same number of freedom degree by knots.

All the models, the length of each streach of members beyond of the intersection was of the 3 to 3,5 times of the their diametre, like this boundary conditions, the real of the shapes in the end and the actions loads in the of the members no influence in the distribute of stress in the regions of concentrations of stresses in the intersections.

For the determination of vary of crest stresses, the ends of the trunk are link by elastics restriction. The loads are link in the end of all members trunk and branch, already that joint are equilibrium, yhe reactions in the restriction result null.

\subsection{Finites Elements Models}
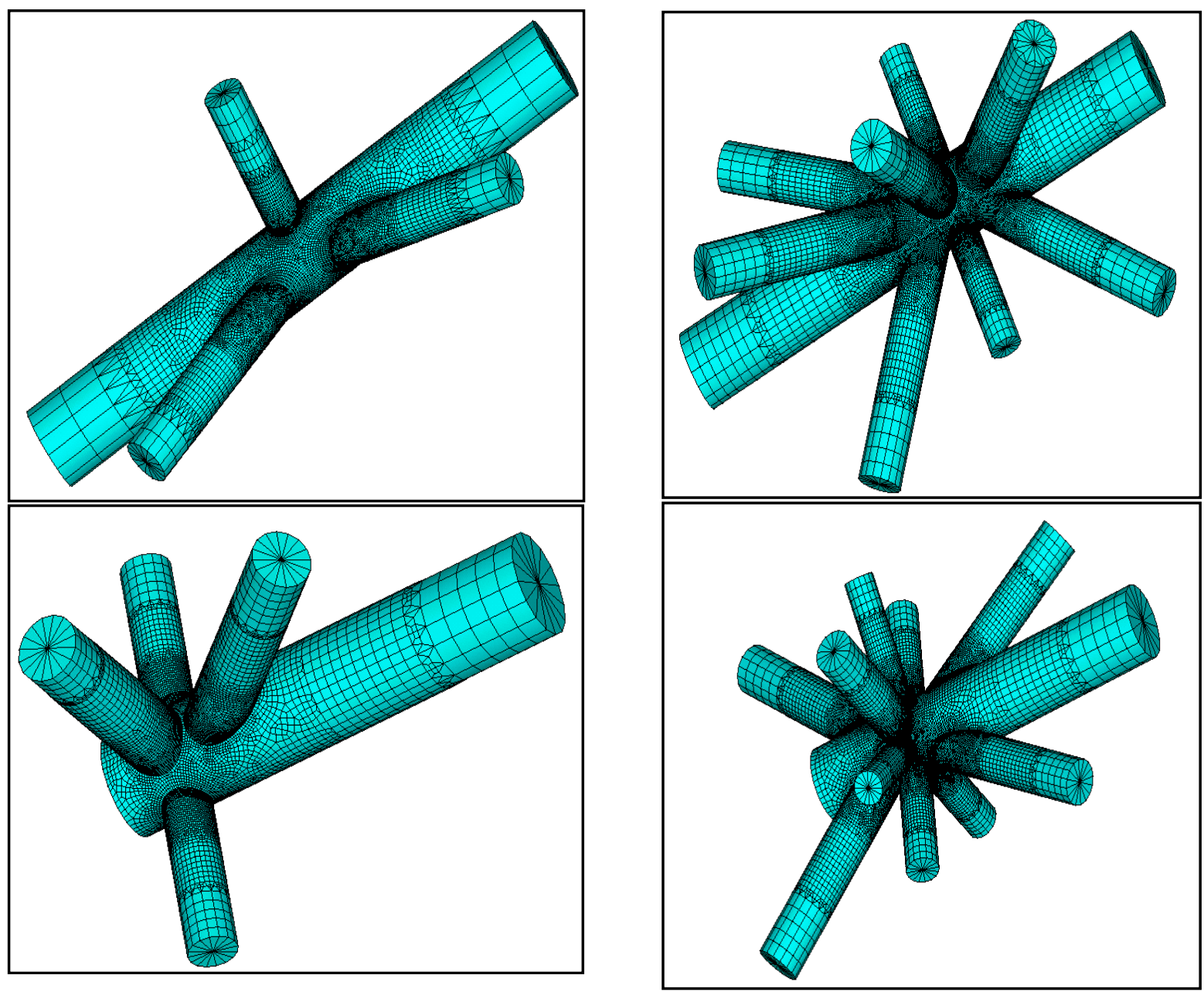

Figura 4- MEF's das juntas 5600,121, 429 e 555. 


\section{RESULTS}

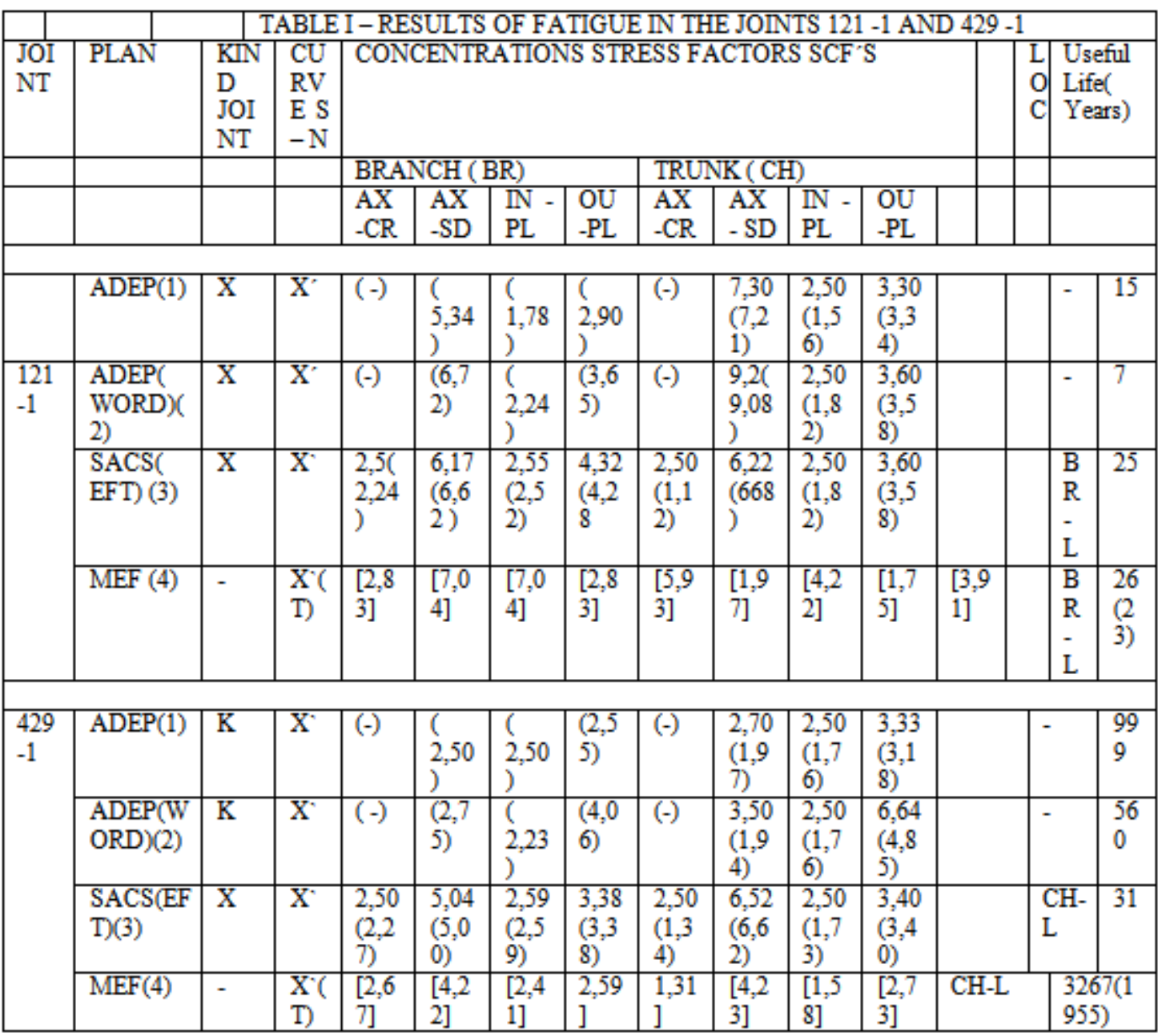

1- $\quad$ SCF's out brackets was calculation by software with length of trunk $\mathrm{L}=4,81 \mathrm{~m}(121)$ and $\mathrm{L}=10,04 \mathrm{~m}$ ( 429). $\mathrm{SCF}_{\min }=2,50$.

2- $\quad$ SCF's in of brackets calculated by parametrics expressions with $\mathrm{L}=4,81 \mathrm{~m}$ ( 121 ) and $\mathrm{L}=10,04 \mathrm{~m}$ 429). in of brakets results by MEF.

(1)Recomendations Expressions of the concentrations stresses factors in Naess( 1985) Ref/1/.

(2) Expressions wordsworth/Smedley for joint X and Kuang/ Wordsworth for joint K.

(3) Expressions of Efthymion, Ref/3/, with corretion of short trunk $(\alpha<12)$

(4)Results by MEF where $\mathrm{L}=9,15 \mathrm{~m}(121)$ and $\mathrm{L}=14,27 \mathrm{~m}(429)$.

Conclusion

The diferentiate betweem the results for the life the fatigue by plan ADEP and SACS and by analysis of MEF to happen no only by fiference betweem the SAC's, but also by behaviour of the joints that, in general, no show the reality in the normal kinds by classifications by plans.

The utilizations of SCF's for design of the life fatigue use simple hipothesis have very questions with final results unpredictable. From this classification of kind of joint can to be to make automatic by plans, stay caracterization a simple joint, limite by kind planar existing, without consideration of the real distribution of strength in each load of the wave.

The great advantage of assessement of fatigue by MEF is the extrapolations of stress método for results of crest stress. All show that searchs are necessary for create tecnics of extrapolations more reliable, verify by results of experimental, apply in models in average surfasse discretizad by shell elements.

The analise by Finites Elements is recomendation for joints that no show kind and/or behaviour same with the models shows by plans. For 4 joints analyseds, two shows that can to be removed of inspect plan underwater.

Bibliography

/1/.ALMAR-NAESS, A. (1985) - Fatigue Handbook - Offshore Steel Structure, Tapir, 520p, Trondheim, Norge. 
/2/. DET NORSKE VERITAS- RECOMMENDED PRACTICE RP-C203 (2000)- FatigueStrenght Analysis of Offshore Stell Structures, 100p, Norway.

13/. EFTHYMIOU, M. (1988) - Development of SCF Formulae and Generalised InfluenceFunctions for Use in Fatigue Analysis - Recent Developments in Tubular Joint Technology, OTJ'88, 34p, London.

14/. HEALY, B.E. \&BUITRAGO, J. (1994). Extrapolation Procedures for Determining SCF'sin Mid Surface Tubular Joint Models - Tubular Structures VI, Grundy, Holgate \& Wong (eds), V.6, p. 651-659, Rotterdam.

15/. PETROBRÁS (1995). Sistema de Reanálise Estrutural da Plataforma de Cherne 2, Memórias de Cálculo e Relatórios, Rio de Janeiro.

Endereço autor: R.Gustavo Sampaio,223/1001,Rio,R.J. CEP:22010-010

E-mail: rtaier@ig.com.br 